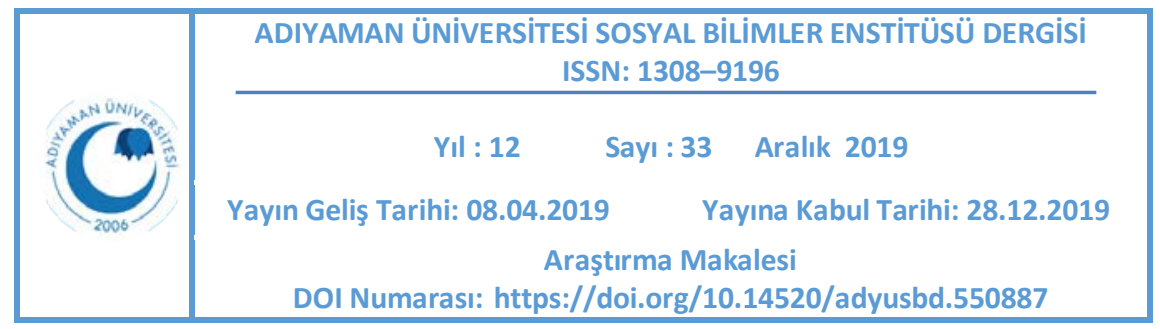

\title{
GÜRÜN ULU CAMii*
}

\section{Fuat ŞANCI**}

\begin{abstract}
$\ddot{O} z$
Sivas'ın Gürün ilçesinde bulunan Gürün Ulu Camii'nin ilk inşası 15. yüzyılın üçüncü çeyreğinden önce olduğunu düşündüğümüz yapının ilk onarımı 1850 olup, bu onarımın tamamlanması ise 1922 tarihlerinde gerçekleştirilmiştir. Günümüze çeşitli değişikliklerle ulaşan yapı, ilk inşa şeklini kaybetmiş olmasına rağmen mevcut planı ve süslemeleri ile Türk sanatının belli bir döneminin önemli özelliklerini yansıtmaktadır. Yapının orijinal duvarlarında bulunan mazgal pencereler kitabede belirtildiği gibi, yapının aslında tonoz veya ahşap tavanlı ve dış kısmın toprak damlı olduğunu teyit etmektedir. Gürün Ulu Camii; son şekliyle merkezi planlı bir yapı olarak Türk İslam mimarisinde Karahanlılar'dan günümüze kadar küçük farklılıklarla uygulanmış bir cami planıyla karşımıza çıkmaktadır. Yapıda merkezi plan; ortada dört sütün tarafından taşınan kubbe, kubbeyi dört yandan destekleyen devirimli tonoz (yarım tekne tonoz) ve köşe boşluklarını örten aynalı tonozlar şeklinde uygulanmıştır. Yapının mihrap ve minberi Osmanlı batılılaşma dönemi üslubunun taşrada ki temsilcisi durumundadır. Mihrabın genelinde yüzeyler akant yapraklı konsollar, yastıklı başlıklar ve yatay silmelerle süslenerek; yivli sütunların dikey etkisi dengelenmeye çalışılmıştır. Bu uygulama Avrupa'daki Neo-klasik üslubun geometrik alanlara bölünmüş düzen anlayışının bir yansıması olarak değerlendirilebilir.
\end{abstract}

Anahtar Kelimeler: Batılılaşma, merkezi plan, Ulu cami.

\footnotetext{
* Bu makale; I. Uluslararası Niğde Dil, Kültür ve Tarih Sempozyumu'nda (3-6 Mayıs 2012) sözlü olarak sunulmuştur.

** ID Dr. Öğr., Adıyaman Üniversitesi, Fen-Edebiyat Fakültesi, Sanat Tarihi Bölümü, fsanci@adiyaman.edu.tr
} 


\title{
GÜRÜN GRAND MOSQUE
}

\begin{abstract}
The first restoration of Gürün Ulu Camii [the Great Mosque of Gürün] located in the Gürün district of the province of Sivas in Turkey and believed to be built before the third quarter of the 15th century was started in 1850, while this restoration process was completed in 1922. The building, which has reached our time with various changes, reflects the significant characteristics of a period of Turkish art with its remaining plan and ornaments, although it has lost its original form of construction. The outwardly-splayed windows on the original walls of the building confirm that the building, as described in its epigraph, actually had a vault or wooden ceiling, and the outer part was earth-sheltered. Gürün Ulu Camii has a mosque structure that has been applied in the TurkishIslamic architecture since the Karakhanids up to our times with small alterations as a centrally planned structure. The central structure of the building was implemented with a dome in the middle carried by four pillars, a barrel vault that supports the dome from four sides and mirror vaults that cover the gaps in the corners. The altar and minbar of the building are a rural representation of the style of the Ottoman Empire in its westernization period. In most of the altar, by ornamentation of the surfaces with cantilevers designed with acanthus leaves, cushioned timber and horizontal moldings, it was aimed to balance the vertical effects of the grooved columns. This practice may be considered as a reflection of the understanding of a plan divided into geometric areas in the neo-classical style in Europe.
\end{abstract}

Keywords: Westernization, central plan, Grand mosque.

\section{GiRiş}

Gürün, Sivas ilinin güneyinde, Kayseri-Malatya kara yolu üzerinde kurulmuştur. İlçenin doğusunda Malatya, batısında Kayseri, güney doğusunda Kahramanmaraş, kuzeyinde Sivas'ın Kangal ilçesi yer almaktadır. M.Ö. 2000'li yıllarla tarihlenen mağaralar ve geç Hitit dönemine ait Şuğul bölgesindeki yazıtlar, ilçenin tarihinin oldukça eskiye dayandığını göstermektedir (Sivas ì Yıllı̆̆ı,1996:96). Bizans döneminde Sebasteia Thema'sına bağlanarak Gaurania olarak anılan bölge, Müslüman Arap ordularının Anadolu'da giriştikleri fetih 
hareketleri sırasında (VII. Yüzyıl)fethedilmiştir(Honigman,1970:171; Yıldız, 1982: 488; Kaegi, 1992: 181-204.; Ostrogorsky, 1986:102-115.; Denizli,t.y:322).

Çeşitli dönemlerde Bizans ve İslam devletlerinin egemenliğine giren bölge, Türklerin 1071 Malazgirt zaferini müteakiben Anadolu'da kurulan ilk Türk beyliği olan Danişmentliler'in egemenliğine girmiş; 1164 yılında Danişmentli Beyi Yağubasan'ın ölümüyle 1165 'te II. Kılıçarslan tarafından Anadolu Selçuklu Devleti'nin idaresi altına alınmıştır (Sevim, 1972: s.219.; Sevim, 1988: 29.; Sevim ve Yücel, 1993:17,18). Bölge, daha sonra Eratnalılar, Memluklular (Sevim ve Yücel,1990:342), Dulkadirliler (Yücel,1989, :7 vd ), ve Osmanlılar (Mehmet Neşri,1987:335: Hadîdî, 1991:124, Aşıkpaşazede, 1992: 65; Anonim,1992:37). arasında el değiştirmiş; nihayet 1516 yılından itibaren kesin olarak Osmanlı idaresine girmiştir (Arifi Paşa;t.y, :550; Tekindağ,1968:31). 1530 tarihli tahrir defterinde Gürün, Sivas eyaletinin Divriği Sancağına tabii, Darende Kazasına bağlı bir nahiye idi (Akkoyun; 1992:22: Temel, 1969:24). 1858 yılında Sivas iline bağlı bir ilçe konumuna getirilmiş olup; halen bu konumunu devam ettirmektedir

\section{Plan ve mimarisi}

Kuzeyden güneye doğru hafif meyilli bir arazi üzerinde kurulmuş olan cami, tromp geçişli kubbeyi dört yandan destekleyen devrimli tonoz ve dört köşe boşluğunu örten dört aynalı tonozdan meydana gelen merkezi planlı bir yapıdır (Resim 3,Çizim 1). Caminin batı cephesini, ampir üslupta ele alınmış bir tali giriş ve hafif şişkin sivri kemerli iki altlık pencere ve bunların arasına yerleştirilmiş üst seviyedeki mazgal pencereler hareketlendirmektedir (Resim 4). Caminin üzerine kurulu olduğu arazinin eğiminden dolayı batıdan doğuya doğru yükselen bir cephe görünümündeki güney cephesi, dört pencere ile sekilendirilmiş ve bu cephede dört altlık ve bunların arasında iki üstlük mazgal pencere yerleştirilmiştir. Bu mazgal pencereler çok dar olarak ele alınmış olup; birer 
ışıklık şeklinde değerlendirilmiştir. Ancak söz konusu pencereler günümüzde iç mekâna yansımamaktadır. Son onarımlarda bu pencerelerin kapatılmış olabileceği düşünülmektedir (Resim 4,5). Bu ışıklıklar batı, güney ve doğuda olmak üzere üç dış cephede tespit edilebilmektedir. Yapının doğu cephesi ise diğer pencerelerle aynı üslupta ele alınmış; üç altlık ve iki ışıklık ile hareketlendirilmiştir (Resim 4). Günümüzde caminin kuzey cephesini iki katlı pencere düzenine sahip muhdes son cemaat mahalli şekillendirmektedir (Resim 5). Ancak caminin soncemaat mahallline açılan asıl kuzey cephesini, üç pencere ve ana eksen üzerindeki taç kapı belirlemektedir ( Resim 6). Caminin kuzey batı köşesinde yer alan minare kaidesi bu cepheden hafif taşıntı yapmaktadır. Kısa tutulmuş kare kaideden silindirik gövdeye prizmatik üçgenlerle geçilmiştir. Bu geçiş elamanlarısekizgen gövdeye geçişte kullanılırken burada silindirik gövde bunların arasına sıkıştırılmış gibidir. Bu sebeple kaideden gövdeye geçişte bir uyumsuzluk meydana getirmiştir (Resim 7).

Yapının ana ekseni üzerinde yer alan taçkapı, kademeli silmelerin meydana getirdiği çerçeve içerisinde, kapı sövelerinin üzerindeki iki kademeli silmeden oluşan başlığa basan yuvarlak kemerden oluşmaktadır. Kapı kemerinin kilit taşı dışa taşıntılıdır. Genel kompozisyon içerisindeki sadeliğine karşı taçkapının kapı kanatları, simetrik altı pano şeklinde bölünmüş ve içlerine kabartma grillandlar, vazolar işlenmiştir (Resim 8).

Taçkapıdan geçilen iç mekân, beden duvarlarından ve kubbe kasnağında yer alan pencerelerden sızan ışıklarla aydınlatılmıştır. Altlık pencereler, dış cephede olduğu gibi iç mekâna da hafif şişkin sivri kemerler şeklinde yansıtılmıştır. Girişin batısında iç mekâna taşan minarenin kare gövdesi yer alır (Resim 9). Minarenin girişi, minare kaidesinden iç mekâna açılan bir kapı ile temin edilmiştir. Minare kaidesinin batısında yer alan pencere, son cemaat mahallinin ikinci katına geçiş 
vermek için düzenlenmiştir. Kıbleyi belirleyen mihrap ile minber, kıble duvarına hareketlilik katmaktadır (Resim 10).

İç mekânı üst örtüyü taşıyan dört sütun ve duvar yüzeylerinden ileri taşan duvar payeleri ile kemerlerden oluşan taşıyıcı sistem şekillendirmektedir. İç mekânda kubbeyi taşıyan kemerler daha yüksek ve geniş tutulmuşken, tekne tonozları taşıyan kemerler daha kısa tutulmuştur (Resim 11). Üst örtünün iç mekândaki bu kademelenmesinin, dışa da yansıması gerekirken; sonradan yapılmış ve üst örtüyü kapatan çatı sebebiyle, bu kademelenme dışarıda etkisini kaybetmiştir (Resim 5).

Yuvarlak kemerli mihrap nişi, iki yandaki kaidelerin üzerine yerleştirilen korint başlıklı, ikişer yivli sütunla sınırlanmıştır (Resim 10, 12). Bu sütunlardan dışta bulunanların üzerine, sarılmış sarmaşıklar işlenmiştir. Kaidelerin yüzeyleri iki pano şeklinde ele alınmış ve her bir pano içerisine, vazolara asılı birer askı çelenk yerleştirilmiştir. İçteki sütunların arasında ve kavsaranın üzerinde Kelime-i Tevhid'in yazılmış olduğu bir panoya yer verilmiştir. Bu panonun ortasında, ileri taşkın bir kilit taşı görünümünde başlık ve aynı hizada "S" kıvrımlı yaprak motifleri ile tezyin edilmiş konsollar yer almaktadır. Bunların üzerinde ise Ali imran süresinden alınan "küllema dehale aleyha Zekeriyye'l-mihrap" ayeti yer almaktadır.

Ayet kitabesinin üzerinde, içteki konsolların yukarısında, buketten fışkıran iri ve kıvrık dallardan meydana gelen bir taç bulunmaktadır. Batılılaşma dönemi özelliğini gösteren oval bir kartuş, bu taç kısmın merkezine yerleştirilmiştir. Taç kısmı, dıştaki sütun başlıklarına oturan yivli payeler, üzerinde "S" kıvrımlı akant yapraklı konsolların taşıdığı arşitrav görünümlü korniş tarafından çerçevelenmektedir. Mihrap yüzeyinde yivlerin oluşturduğu dikey gelişme, aynı hizada yer alan başlık ve konsolların oluşturduğu yatay hat ve kaidenin dikey 
çizgileri birbini dengelenmiştir. Konsolların taşıdığı korniş üzerinde, heykeli andıran karşılıklı biblolara yer verilmiştir (Resim 12).

Vazo seklinde kaidelere oturan sütunlar ve bunları bağlayan yuvarlak kemerin oluşturduğu minber kapısı, yine aynı şekildeki kaidelere oturan korint üsluptaki sütünce ve dilimli kemerlerden oluşan köşk kısmı, barok üslupta bitkisel süslemelerle doldurulmuş aynalıkları ile minber batılılaşma dönemi özellikleri göstermektedir. Mihrabın sütuncelerinin ileri taşkın olması nedeniyle köşk altında bulunması gereken kemer, ileri alınmış ve bu kısım yivli payecikleri birbirine bağlayan yuvarlak kemer, üstten yumurta dizilerinden oluşan ikinci bir kemerle kuşatılmasıyla meydana getirilmiştir (Resim 12). Aynalıkları dışarıdan çerçeveleyen kenar suyu, karenin ikiye bölünmesi ile elde edilen karşılıklı iki üçgenin ardı ardına sıralanmasıyla oluşturulmuştur. Bu şema, üçgen şeklinde tasarlanmış çiçek motiflerinden meydana getirilmiştir (Resim 13).

Kuzey cephede duvar içerisinde kare kaidenin üzerinde silindirik olarak yükselen minare, üst örtü seviyesi üzerinde şişkin bir papuçluktan sonra tekrar silindirik bir gövde şeklinde yükselir. Alttan ve üstten birer bilezikle sınırlanan gövdeden, taş korkuluklu şerefeye, iç ve dış bükey silmelerden oluşan bir şerefe altığı ile geçilir. Şerefe altlığının üst kısmında zikzaklı bir kuşak ve onun üzerinde daha

küçük yarım dairelerden oluşan ikinci kuşak bulunur. Şerefe korkuluklarının üzerinde, kartuşlar içerisinde çeşitli süslemeler yer alırken; korkuluğun üzerinde inci dizilerinden oluşan bir friz yer alır (Resim 14). Minare, silindirik petek kısmı ve sivri külah üzerine yerleştirilen taş bir âlemle sonlanır (Resim 5).

\section{Karşılaştırma ve Değerlendirme}

Gürün Ulu Camii'nin son şeklini XX. yüzyılın ilk çeyreğinde aldığı; üzerinde bulunan kitabelerden anlaşılmaktadır. Illk kitabede, cami ve mihrabın harap olduğu belirtilmiştir. Ancak yapılan onarımın aynı plan üzerine yapılıp 
yapılmadığı; yani yapının harabiyet ve onarım dereceleri kitabelerden anlaşılamamaktadır. Kitabede yapının dam ve eyvanlarının harap olduğuna dair bilgiler, caminin düz dam örtülü olduğunu açıkça ortaya koymaktadır.

Yapının bugünkü mevcut haliyle üst örtüsünün sonradan değiştiği izlenimini uyandıran bazı işaretler de mevcuttur. Yapının güneyinde yer alan tonoz örtülerin dar, kuzeydekilerin geniş oluşu, üç cephede de dışardan görülen; ancak içerden karşılığı olmayan mazgal pencereler, ciddi bir değişime işaret etmektedir. Mazgal pencereler oldukça alt seviyede kalmış durumdadır. Beden duvarlarının yeni örtüyü oturtabilmek için yükseltildiğianlaşılmaktadır. Mazgal pencerelerin düşük kotta bulunması, kitabede belirtildiği gibi yapının düz dam veya tonoz örtülü olabileceğine işaret etmektedir. Çünkü merkezi plan gibi gelişkin bir plan anlayışında mazgal pencere uygulaması ile karşılaşmış değiliz. Bu pencereler yapıda bir plan değişikliğine gidildiğini göstermekte olup, mazgal pencereler ilk inşadan yani 1850 onarımından önceye ait olmalıdır. Birinci onarımda yapının, dam, eyvan ve mihrabının harap olduğu kitabede açıkça yazmaktadır.

İkinci kitabe, yarım kalmış bir onarımdan bahsetmektedir. Bu onarımın 1922 yılında gerçekleşmiş olması nedeniyle, dönemin siyasi özellikleri dikkate alınarak değerlendirme yapılmalıdır. Ülke topraklarının işgal altında olması, böyle büyük bir inşa faaliyetinin zorluğunu ortaya çıkarmaktadır. Bu nedenle merkezi planın, 1850 yılındaki onarımda gerçekleşmiş olabileceğini düşünmekteyiz.

Cami'nin kuzey cephesinde yer alan minarenin kuzey duvarından ileri taşmış olması, yapının kuzeye doğru, 1850 yılı onarımında genişletilmiş olduğunun bir göstergesidir. Bu genişletme; merkezi planlı yapının kıble yönünde yer alan kısımların daha dar; kuzey yönündekilerin ise daha geniş tutulmasında da görülmektedir. Bu durum, merkezi kubbenin yerleştirilmesi için gerekli olan kare alanın oluşturulabilmesinden kaynaklanmış olmalıdır. 
Yapının planı son şekli ile ele alındığında, geleneksel olarak Türk mimarisindeki kökünün, Anadolu öncesi Türk mimarisine dayandığı görülür. Merkezi planlı cami geleneğinin bilinen ilk örneği, Karahanlılar'ın XI. yüzyılda inşa ettikleri kışlık Hazara Camisi'dir (Plan2) (Cezar, 1977: 148, 149;Aslanapa, 1984:20). Yapıda yer alan merkezi kubbe, dört yandan çapraz tonoz örtüyle desteklenmiş ve köşe boşluklarında ana kubbeden daha küçük ölçüdeki kubbeler kullanılmıştır. Merkezi plan şemasının Anadolu'da uygulandığı ilk yapı Danişmend Gazi dönemine tarihlendirilen (1086-1104) Tokat Garipler Camii olup; bu plan, merkezdeki kubbe dört ayak ve bunların aralarına yerleştirilen sütunlardan oluşan bir taşıyıcı sistem üzerine yerleştirilmiştir. Bu düzenleme, köşe kubbelerinin ve yanlardaki tonoz örtülerin kaldırılıp, merkezi kubbenin beşik tonozlarla çevrilmesi ile elde edilmiştir(Plan 3) (Cantay, 1977: 25-27; Mülayim, 1996: 381-382; Gündoğdu vd., 2006:33-34.; Şahin, 2018:219, 211-251). Bu yönü ile Hazara camisinden ayrlır. Merkezi plan türünün Anadolu'da uygulandığı ikinci yapı, üst örtüsünün orijinalliğinde bazı kuşkular olan Çemişgezek, Yelmaniye Camisi'dir (1397- 1406). Bu eserde merkezi kubbe dört yönden beşik tonozlarla desteklenmiş ve köşelerde uzun beşik tonozlar kullanılmıştır ( Sözen,1979: 39).

Osmanlı mimarisinde, günümüze ulaşan en erken tarihli merkezi planlı yapı olan Atina Fatih Camii'nde dört ayağa oturan merkezi kubbe, dört yandan yarım kubbelerle desteklenmiştir(Plan 4) (Eyice, 1954: 161-163; Aslanapa, 1966: 477485; Ayverdi,1973:49-55; Çam, Ankara, 2000:13). Bu yapıda köşe boşluklarının kubbeciklerle örtülmesiyle ilk örneklerden ileri bir adım atılmıştır. İstanbul Şehzade Camii'nin ana çizgileri basit de olsa yakalanmıştır. XVI. yüzyılda merkezi planın uygulandığı Elbistan Ulu Camii (1516-1522) (Gündoğdu, 1986, 24), Diyarbakır Fatih Paşa Camii (1520) (Sözen, 1975:67-69; Yüksel, 1983:424.; Aslanapa, 1986: 152) ile bugünkü şeklini 1863 yılında alan ve orijinal plan üzerine kurulmuş olduğunu kabul etmemiz halinde Adıyaman Ulu Camii'de (Plan 5) (Gündoğdu, 1986:86) coğrafi konum itibarı ile Gürün'e yakın camilerdir. 
Yukarıdaki örneklerden ilki hariç diğerleri Sinan'ın İstanbul Şehzade Camiini inşa etmeden önce görmüş ve incelemiş olabileceğini tahmin ettiğimiz yapılardır. Mimar Sinan bu yapıların aksayan yönlerini görüp; 1538-1548 yılları arasında bu denenmiş modelleri yeniden değerlendirerek, olgunluğu Şehzade Mehmet Camisi'nde yakalamıştır (Aslanapa,1986:183-183).

Bu plan türü daha sonra Keban Yusuf Ziya Paşa Camii (1794-1795) (Plan 6), Erzincan Hacı İzzet Paşa Camii(XIX. yüzyılın II. çeyreği) Malatya Yeni Camii(18891910) (Kuran, 1986:64) gibi yapılarda uygulanmıştır(Sözen, 1970:16, Gündoğdu, 1992:87; Şancı, 1995:218).

Bu yapılardan Keban Yusuf Ziya Paşa Cami'inde Tokat Garipler Cami'indeki gibi dört köşe kubbesine yer verimemiş tonozlarla örtülmüştür. Gürün Ulu Cami'inde köşe boşluklar aynalı yonozlarla örtülürken Atina Fethiye Cami, Diyarbakır Fatih Paşa Cami gibi erken örneklerde de bu alanlar kubbelerle Örtülmüş olduğu görülür. Gürün Ulu Camii köşe boşlerde kubbe yerine aynalı tonoz kullanılmış olması ile biraz arkaik özellik gösterir. Nitekim Adıyaman Ulu Cami, Malatya Yeni Cami'inde köşeler kubbelerle kapatılmış beşik tonoz örtüler ana kubbeye dik uzatılmıştır. Bu uygulama diğer yapılarda görülmemektedir. Bu örneklerin Gürün ile hemen hemen aynı bölgede oluşu ve ilk örneklerin de bu coğrafi alanda uygulanmış olması, Anadolu öncesi Türk mimarisi ile ilişkilerinin kuvvetine işaret etmektedir. Bu plan türünün Osmanlı mimarisinde XVI. yüzyıl başlarından itibaren farklı bölgelerde uygulandığı görülmektedir. Bunlar; Hacı Hamza Sinan Bey Camii(1506-1507), Kara Oğuz Köyü Camii (XVI. yüzyılın ilk çeyreği), İstanbul Şehzade Mehmet Camii(1548), Payas Sokullu Mehmet Paşa(1574), Tunus Sıdı Mahrez Camii (XVII. yüzyılın sonu), Kahire Kavalalı Mehmet Ali Paşa Camii (1828-1847), Balıkesir Zağanos Paşa Cami'leridir (1900) (Sözen, 1970: 16). 
Osmanlı Devletinin XVIII. yüzyılda, Batı karşısında zayıflaması, Osmanlı idaresinin yüzünü Batıya çevirmesine neden olmuştur (Akdağ, 1974:391-394). Bu durum sanata dolayısı ile de mimariye yansımıştır (Renda, 1977:15). Batıya gönderilen elçiler ve oradan gelen sanatçılar ile Batıya özenmiş yönetim kadrosunun teşvikleri, daha sonraki dönemlerde oluşan estetik hazdaki köklü değişikliklerin hazırlayıcısı olmuştur (Kuban, 1982: 117).

XVIII. yüzyılda Osmanlı mimarisindeki değişim, bezemede başlar ve XIX. yüzyıla kadar bu çizgide devam eder (Kuban, 1982:117). Bu dönemde belirgin yeniliklerin, ayrıntıların ele alınmasında ve süslemede ortaya çıktığı; Nuru Osmaniye Camii'nde olduğu gibi genel planlamada Türk sanat geleneğine özgü yorumun devam ettiği görülür.

Gürün Ulu Camii'nin mimarisinde, Türk mimari geleneğinin devamlılığına karşı özellikle mihrap ve minberdeki dekorasyonunun yabancılı̆̆ı dikkat çekmektedir. Mihrap nişini iki yandan sınırlandıran çifte sütunlar ve bunların taşıdığı kornişten oluşan kütlesel görüntüsü ile Nuru Osmaniye Camii (1748-1755) avlusunun taç kapısını ve I. Abdülhamit İmareti (1774-1880) (Aslanapa, 1986:390) taçkapısını hatırlatır. Kornişi taşıyan plastırların konsol biçiminde akant yapraklarıyla şekillenmesi III. Selim Dönemi’nin (1789-1880) özellikleridir (Aslanap,1986:39) Şah Sultan (1792) ve Ayşe Hatun (1794) çeşmelerinde görülen yivli plastırlar, daha önceki gelişmeler olup; (Arel, 1975:8; Ekiz, 2006: 63 vd.) "S" şeklindeki akant yaprakları bu yapılarda yeni yeni ortaya çıkmıştır. Bu özelikleri ile Gürün Ulu Camii, Barok ve Ampir özellikleri bir arada taşımaktadır. Mihrabı üstten sınırlandıran korniş üzerine yerleştirilen vazolar, Gülşehir Vezir Kara Mehmet Paşa Camii'nde de (1779) görülür (Arel, 1975:88). Yivli plastırlar, girlantlar (askıçelenk), kabarık stilize bitki motifleri, "S" şeklindeki akant yapraklı konsollar, yastıklı ve heybetli sütun başlıkları, barok ve ampir üslupları yansıtır. Mihrap ve minberde yüzeyleri doldurmaya yönelik " $C$ " ve "S" kıvrımlı bitkisel 
süslemeler, İstanbul Nusretiye Camii(1823-26) (Kuban, 2007:631) pencere alınlıklarında da uygulanmıştır. Ancak mihrabı üstten sınırlayan korniş üzerindeki üç boyutlu bibloları İstanbul Laleli Camii (1760-64) (Kuban,2007:540) harim girişinde görmekteyiz. Laleli Cami taçkapısında görülen biblolarla olan benzerliği göz önüne alınırsa mihrabı XIX. yüzyılın ortalarıyla tarihlendirmemiz gerekmektedir. Buna göre yapının mihrabının, kitabede de belirtildiği gibi 1850 yılındaki onarımda yaptırıldığını söyleyebiliriz.

Mihrabın genelinde yüzeyler akant yapraklı konsollar, yastıklı başlıklar ve yatay silmelerle süslenerek; yivli sütunların dikey etkisi dengelenmeye çalışılmıştır. Bu uygulama Avrupa'daki Neo - klasik üslubun geometrik alanlara bölünmüş düzen anlayışının bir yansıması olarak değerlendirilebilir (Aslanapa, 1986:449). Minberdeki süslemeler de aynı dönem özelliklerini üzerinde taşımaktadır. Yan aynaların kenar sularındaki bitkisel süslemenin plastik niteliklerinden arınmaya başlayıp, yüzeyselleştiği görülmektedir. Süslemelerin ince oymalara dönüşmesi XVIII. yüzyılın son çeyreğinde başlamıştır (Danel, 1982:25). Bu durum, mihrab süslemeleri ile inşa tarihinin uslup açısından uyumlu olduğunu göstermektedir.

\section{Tarihlendirilmesi}

Yapıyı ilk incelediğimiz 1996 yılında caminin pencere kısmında korunan bir kitabesi bulunmakta idi. 2008 yılında yaptığımız ikinci ziyaretimizde, bu kitabenin Camii Koruma Derneği tarafından camekân içerisine almak amacıyla kaldırıldığını tespit ettik.

Söz konusu kitabe şu şekildedir (Resim 1):

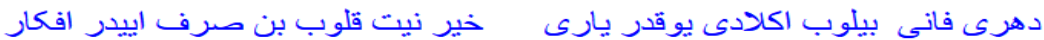

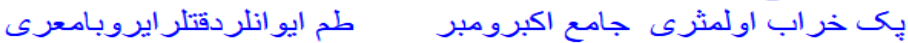

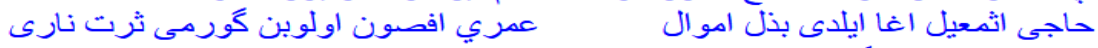

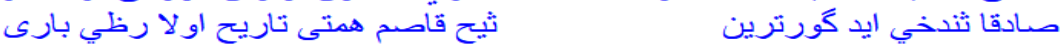


Dehri fânî bilub anladı yokdur yârı

Hayr-ı niyet kıluben sarf ider efkâr ı

Pek harab olmuşdı cami-i ekber ve minber

Damı eyvânları dikkatler idüp i'marı

Hacı İsmail Ağa eyledü bezl ü enva

Ömrü efzun oluben görmeye şiddet-i nârı

Sâdıkâ sen dahiihda idegör tarihin

Şeyh Kasım himmeti tarih ola rızâ yî bârî

(1266/1850) Kitabeden anlaşıldığı üzere, caminin damının ve minberinin harap olması neticesinde yöre halkının yardımları talep edilmiş ve özellikle bu tamiratta yardımları çok olan "Hacı İsmail Ağa"dan bahsedilmiştir. Ebcet hesabı ile tamir tarihi "ola rızâ-yî bârî" ibaresinin karşılığı olan 1266 (1850)ile birlikte verilmiştir. Ayrıca kitabede ismi geçen Şeyh Kasım1845 yılında imamlık görevi yapmaktadır(Eken; 1991,85-95). *

Diğer bir kitabe ise kuzey cephedeki kapının üzerinde, duvara monte edilmiş olan onarım kitabesidir. Bu kitabe şu şekildedir (Resim 2):

\footnotetext{
* 13574 nolu Şuğul Mahallesine ait temettuat defterinde Şeyh Kasım’ı 1845 yılında Ulu Cami'de imamlık yaptığı belirtilmektedir( Galib Eken; "Temettuat Defterlerine Göre Gürün" Revak, Sivas, 1991,85-95). Kitabede ismi geçen Şeyh Kasım Caminin onarımına öncülük etmiş olmalıdır. Kitabedeki 1850 tarihi ve imamlık yaptığı 1845 yıllarının birbirine yakın olması bu iki ismin aynı şahıs olma ihtimalini güçlendirmektedir.
} 


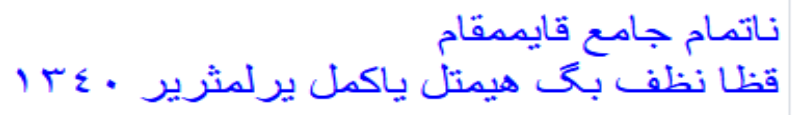

"Na temam cami-i kaimmakam kazai(Kadı) Nazif Bey'in himmetiyle ikmal edilmiştir 1340" (1922).

İkinci kitabe, yarım kalmış bir inşaatın veya tamiratın 1922 yılında Kaymakam Kadı Nazif Bey'in çabalarıyla tamamlandığını göstermektedir. Yapının önündeki son cemaat mahalli daha sonradan (1990'lı yılarda) eklenmiştir.

Yapının ilk inşası hakkında herhangi bir bilgiye ulaşılamamış olmasına rağmen ilk inşadan kalan bazı mimari unsurlar dikkate alınarak bir tarihlemede bulunma imkanı vermektedir. Yapının doğu, batı ve güney cephelerinde bulunan mazgal pencereler ve minare kaidesinde bulunan prizmatik üçgen şeklindeki geçiş öğeleri erken döneme işaret etmektedir(Resim. 3, 4, 5, 7). Minarelerdeki bu geçiş öğeleri Darende Ulu Camii minaresi (1468-1472) (Şancı. 2013:35) ve Maraş Hatuniye camilerinde (1509) (Gündoğdu, 1986:60; Özkarcı, 2007:35) karşımıza çıkmaktadır. Cephelerde yer alan mazgal pencereler Osmanlı mimarisinin gelişmiş bir döneminde kullanılmadığından bu yapıyı Osmanlı öncesine tarihlemek gerekmektedir. Minare kaidesindeki geçişler; bölgede Memluk, Dulkadirli egemenlığinin sürdüğü dönemlere işaret eder. Darende ile olan yakınlık sebebi ile Darende Ulu camii ile çağdaş olmalıdr. Buna göre yapının ilk inşasının en geç 15. yüzyılın 3. çeyreği civarında olabileceğini söyleyebiliriz.

\section{Sonuç}

Sonuç olarak merkezden uzak yerleşim yerlerinde de mimari formlarda geleneksel özellikler korunurken; dekorasyonda, batı etkisinin kendini hissettirdiği bu yapıda da görülmektedir. 


\section{KAYNAKÇA}

Akdağ, M. (1974). “Türkiye'nin Batılılaşmasını Zorunlu Kılan Tarihsel Koşullar, Cumhuriyetin 50. Yıl Dönümünü Anma Kitabı, Ankara Üniversitesi Dil Tarih ve Coğrafya Fakültesi Yayını, Ankara.

Akkoyun, S. (1992). 1530 (H.937) Tarihli Tahrir Defterine Göre Darende Kazası, Basılmamış yüksek lisans tezi, Samsun,

Anonim (1992). Tevarih-i Al-i Osman, Haz. Nihat Azamat, İstanbul: Marmara Üniversitesi Yayınları.

Arel, A. (1975). XVIII. Yüzyıl İstanbul Mimarisinde Batılılaşma Süreci, İstanbul: ITÜ Mimarlık Fakültesi Yayınları.

Arifi Paşa (1331-1332). "Maraş ve Elbistan'da Dulkadiroğlu Hükümeti”, T.O.E.M., Enderun Kitapevi, Tıpkı Basım, İstanbul, No. 33

Aslanapa, O. (1986 ). Osmanlı Mimarisi, İstanbul: İnkılap Kitabevi.

Aslanapa, O.( 1984). Türk Sanatı I-II, İstanbul: Kervan Yayınları.

Aslanapa, O. (1966) Yunanistan'da Türk Eserleri ve Türklerin Durumu” Türk Kültürü, C. IV, S. 41,Türk Kültürünü Araştırma Enstitüsü Yayını, Ankara, 477-486.

Aşıkpaşazede (1992). Aşıkpaşaoğlu Tarihi, Çev. Nihal Atsız, İstanbul: M.E.B. Yayınları.

Ayverdi, E. H. (1973). Osmanlı Mimarisinde Fatih Devri, 855-880, (1453-1481), C. III, İstanbul. 
Cantay, T. (1977). “Bir kuzeybatı Anadolu Gezisinden Notlar”, Sanat Tarihi Yıllığı, S. VII, İstanbul: İstanbul Üniversitesi Yayınları.

Cezar, M.(1977). Anadolu Öncesi Türklerde Şehir ve Mimarlık, İstanbul: İş Bankası Yayınları.

Çam, N. (2000). Yunanistan'daki Türk Eserleri, Ankara: Türk Tarih Kurumu Yayınları.

Danel, S. (1982). Batılılaşma Sürecinde İstanbul'da Tasarım ve Dış Mekânlarda Değişim ve Nedenleri, OTDÜ Mimarlık Fakültesi Yayınları, Ankara

Denizli, H. (t.y) Sivas Tarihi ve Anıtları, Özbelsan A.Ş. Yay., Sivas,

Eken, G. (1991). “Temettuat Defterlerine Göre Gürün” Revak, Sivas, (85-95)

Ekiz, M.(2006). Nevşehir'de Türk Dönemi Mimari Eserleri, Ankara Üniversitesi Sosyal Bilimler Enstitüsü Sanat Tarihi ana bilim dalı yayımlanmamış doktora tezi, Ankara.

Eyice, S.(1954) "Yunanistan'da Türk Devri Eserleri”,Türkiyat Mecmuası, C.XI, 205-230, İstanbul: İstanbul Üniversitesi Yayınları.

Gündoğdu, H.; Bayhan, A. A.; Aktemur, A. M.; Kukaracı, İ. U.; Çelik, A. ve Güneş, B. (2006). Tarihi Yaşatan il Tokat, Ankara.

Gündoğdu, H.(1986). Dulkadirli Beyliği Mimarisi, Ankara: Kültür Bakanlığı.

Gündoğdu, H.(1992). Erzurum Lala Paşa Külliyesi, Ankara.

Hadîdî, (1991). Tevârih-i Al-i Osman (1299-1523), Haz. Necdet Öztürk, İstanbul: Marmara Üniversitesi Yayınları. 
Honigman, E. (1970). Bizans Devletinin Doğu Sınırı, Çev. F. Işıltan, İstanbul: iü Ed. Fak. Yayınları.

Kaegi, W. E. (1992). Byzantium and the early Islamic conquests, New York Cambridge University Press.

Kuban, D. (2007), Osmanlı Mimarisi, İstanbul: YEM Yayınları.

Kuban, D. (1982), Türk ve İslam Sanatı Üzerine Bir Deneme, İstanbul: Arkeoloji ve Sanat Yayınları.

Kuran, A.(1986). Mimar Sinan, İstanbul: Hüriyet Yayınları.

Mehmet Neşri (1987). Kitab-ı Cihan Numa (Neşri Tarihi), Yay. Reşit Unat Mehmet A. Köymen, C.I, Ankara: TTK Yayınları.

Mülayim, S. (1996). "Garipler Camii", İslam Ansiklopedisi, C.13, 381-382, İstanbul: Türkiye Diyanet Vakfı Yayınları.

Ostrogorsky, G.(1986). Bizans Devleti Tarihi, Çev. F. Işıltan, Ankara: TTK Yayınları.

Özkarcı, M. (2007) Türk Kültür Varlıkları Envanteri Kahraman Maraş I 46,TTK. Yaynları,Ankara

Renda, G. (1977). Batılılaşma Döneminde Türk Resim Sanatı 1700-1850, T.T. K., Ankara

Sevim, A. ve Yücel, Y. (1990) Türkiye Tarihi, C. I, İstanbul: TTK Yayınları.

Sevim, A. (1972). "Malazgirt Meydan Savaşı ve Sonuçları", Malazgirt Armağanı, 219-229, Ankara: TTK Yayınları. 
SEVIM, A. (1988). Anadolu'nun Fethi Selçuklular Dönemi (Başlangıçtan 1086'ya Kadar), Ankara: TTK Yayınları.

Sivas İ Yıllığı (1996). Sivas

Sözen, M. (1970) “Keban'da Türk Eserleri”, T.T.O.K. B.,c.27,S.306, Türkiye Turink Otomobil Kurumu,İstanbul,(10-16)

Sözen, M. (1979). “Çemişgezek'te Türk Devri Eserleri ve Yelmaniye Camii”, Sanat Tarihi Yıllığı, S. IV, 2947, İstanbul: İstanbul Üniversitesi Yayınları İstanbul.

Sözen, M. (1975). Türk Mimarisinin gelişimi ve Mimar Sinan, İstanbul: Türkiye İ̧̧ Bankası Kültür Yayınları.

Şahin, M. K. (2018). “Anadolu Selçuklu Döneminde Malatya ve Tokat Çevresinde Bulunan Bazı Yapılar Üzerine Düşünceler/ Remarks on Some Buildings Located Around Malatya and Tokat in Anatolian Seljuk Period", Selçuklu Medeniyeti Araştırmaları Dergisi (SEMA)- Journal of Seljuk Civilizational Studies (JSCS), Yıl:2018, Sayı:3, 211-253.

Şancı, F. (1995). "Kebanda Yusuf Paşa Külliyesi”, D.i.F. Araştırma Dergisi, C.I, S.I i.ü. Darende İlahiyat Fakültesi Yayını, 211-242

Tekindağ, Ş. (1968). "Yeni Kaynak ve Vesikaların Işığında Yavuz Selim'in İran Seferi", Tarih Dergisi, S. 22, 49-78

Temel, M. (1968). Osmanlı Devrinde Darende Tarihi, İstanbul Üniversitesi Tarih Bölümü Basılmamış Lisans Tezi, İstanbul

Turan, O. (1993). Selçuklular Zamanında Türkiye, İstanbul: Boğaziçi Yay. 
Yıldız, H. D. (1982). "Bizans Tarihi”,Anadolu Uygarlıkları Ansiklopedisi, C.III, İstanbul: Görsel Yayınları.

Yücel Y. (1989), Anadolu Beylikleri Hakkında Araştırmalar-Eratna Devleti, Kadı Burhaneddin Ahmet Devleti,- Muttaharten ve Erzincan Emirliği, C.II, Ankara: TTK yayınları.

Yüksel İ. A. (1983). Osmanlı Mimarisinde II. Bayezid - Yavuz Selim Devri (886926/1481-1520), C. V, İstanbul: İstanbul Fetih Cemiyeti Yayınları.

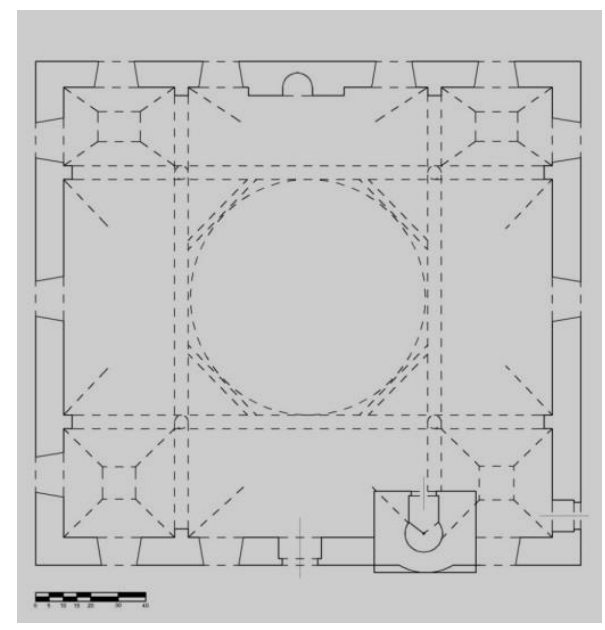

Plan 1. Gürün Ulu Camii Röleve (F. Şancı 1996) 


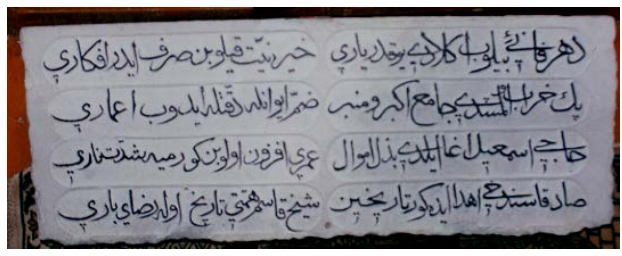

Resim 1. Gürün Ulu Camii 1850 tarihli onarım kitabesi

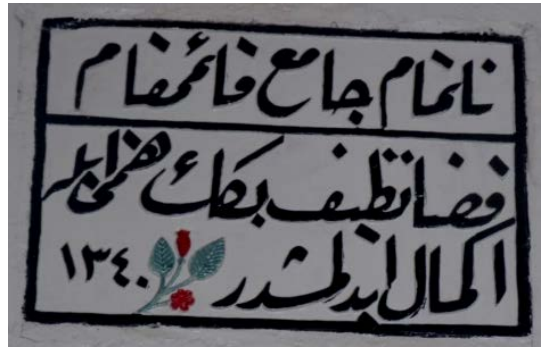

Resim 2. Gürün Ulu Camii 1922 tarihli onarım kitabesi

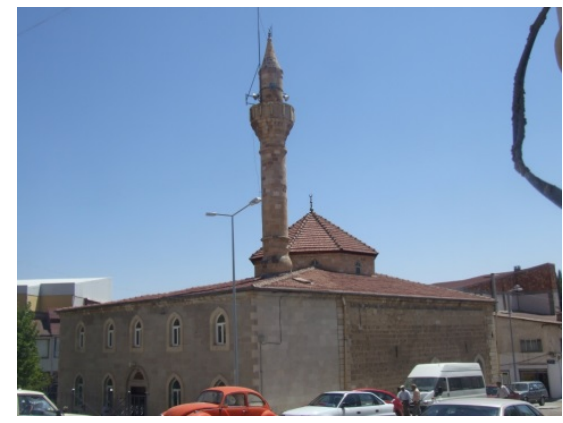

Resim 3. Gürün Ulu Camii kuzeybatıdan görünüş 


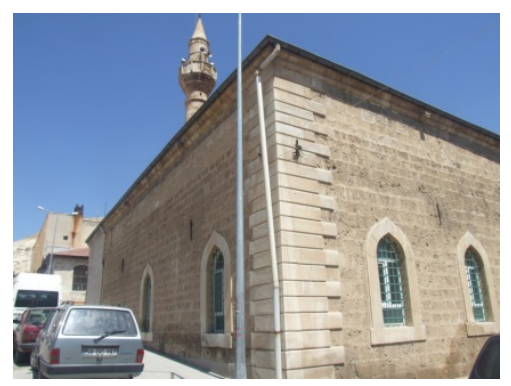

Resim 4. Gürün Ulu Camii güneybatıdan görünüş

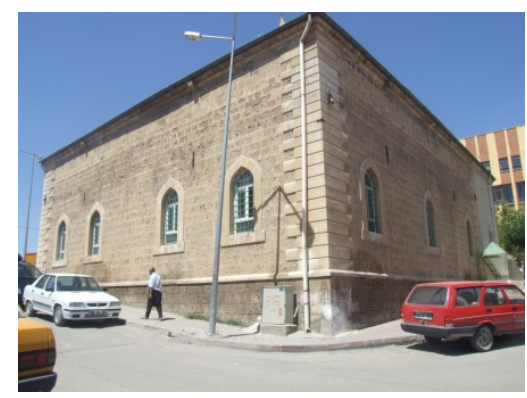

Resim 5. Gürün Ulu Camii güneydoğudan görünüş 


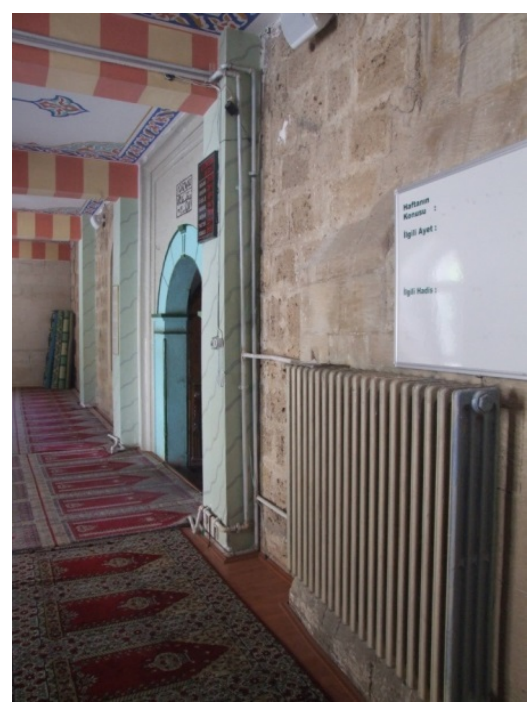

Resim 6. Gürün Ulu Camii kuzey cephesi

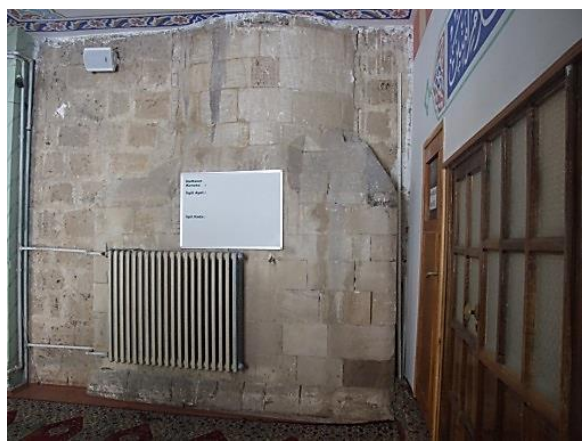

Resim 7. Gürün Ulu Camii kuzey cephesinde minare kaidesi 


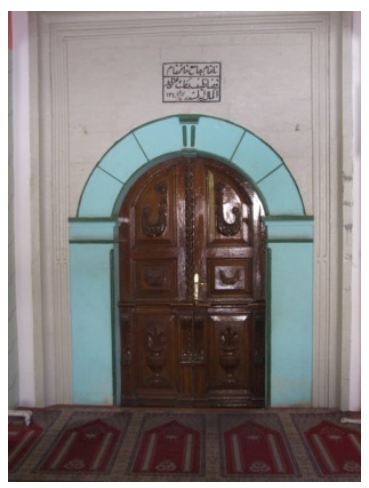

Resim 8. Gürün Ulu Camii kuzey cephesinde giriş kapısı

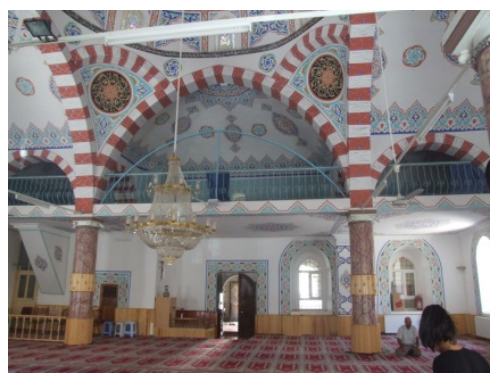

Resim 9. Gürün Ulu Camii iç mekânda kuzey cephesi

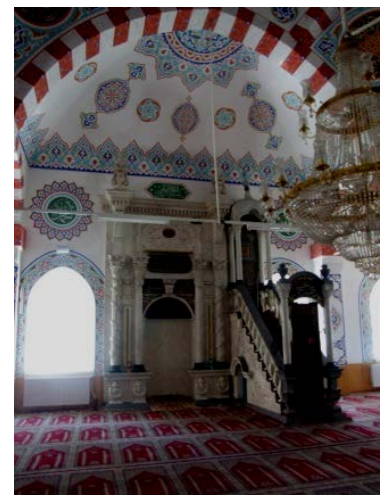

Resim 10. Gürün Ulu Camii iç mekânda güney cephesi 


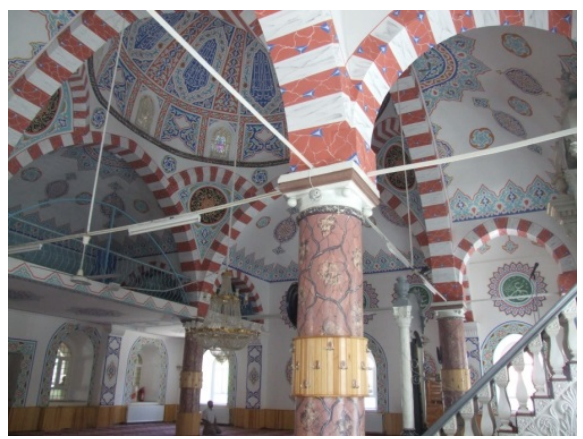

Resim 11. Gürün Ulu Camii iç mekânda doğu cephesi ve üst örtü

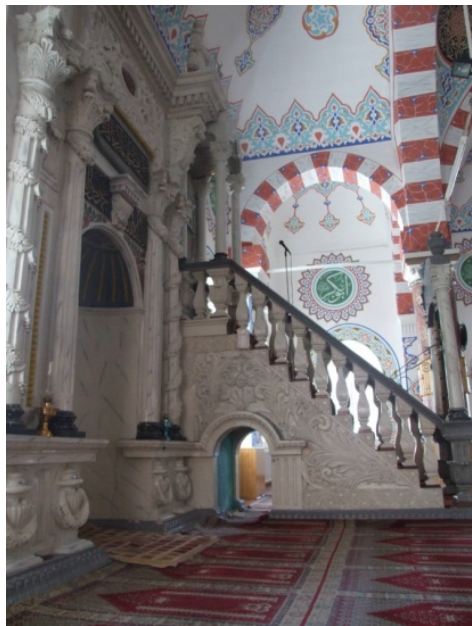

Resim 12. Gürün Ulu Camii 


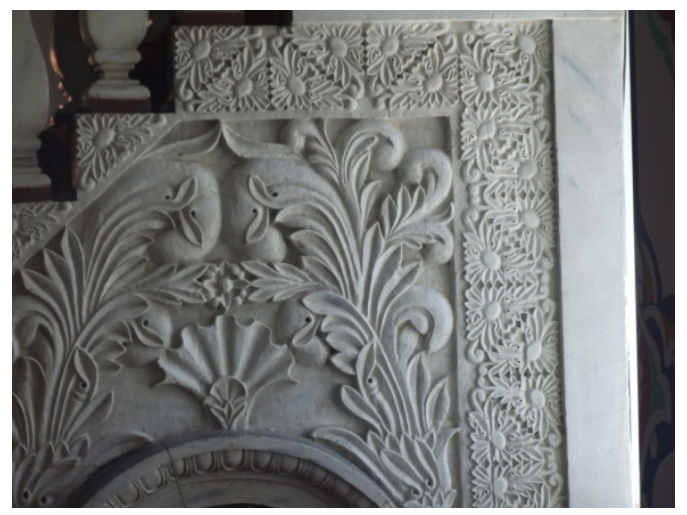

Resim 13. Minberden ayrıntı mihrap ve minber

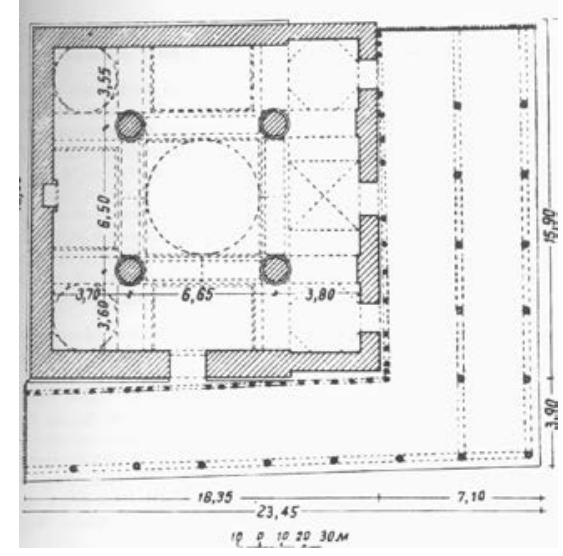

Plan 2. Hazara Camii Planı (M.Cezar'dan) 


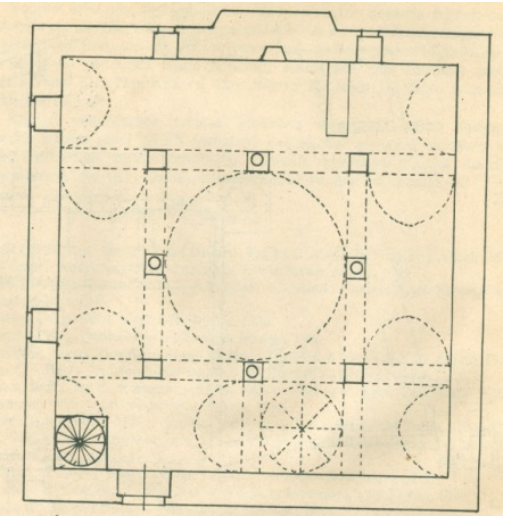

Plan 3. Tokat Garipler Camii (T. Cantay'dan)

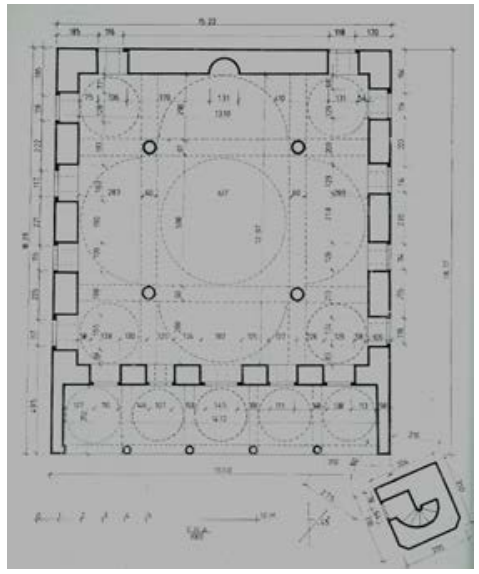

Plan 4. Atina Fehiye Camii (E. H. Ayverdi'den) 


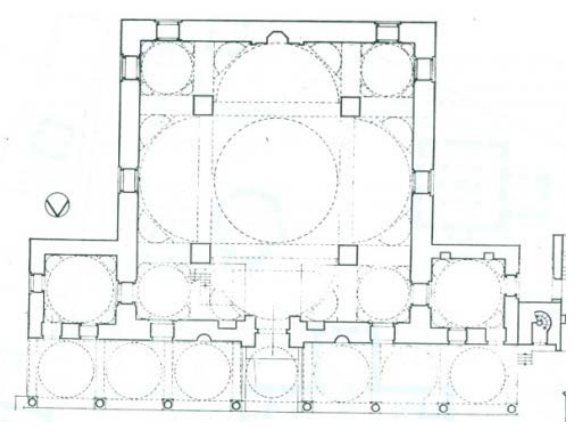

Plan 5. Diyarbakır Patih Paşa Camii(M.Sözen'den)

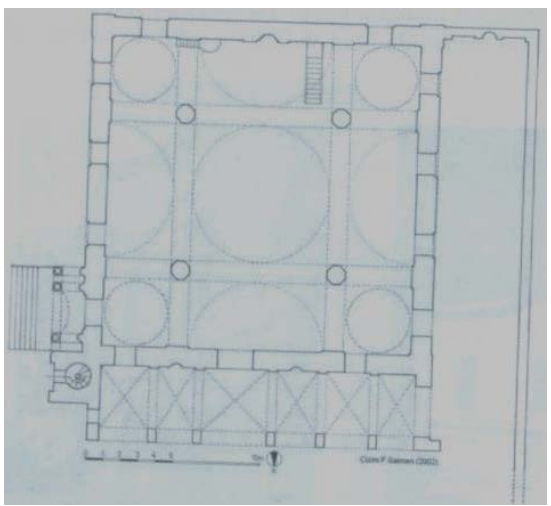

Plan 5. Adıyaman Ulu Camii (A. A. Bayhan'dan) 


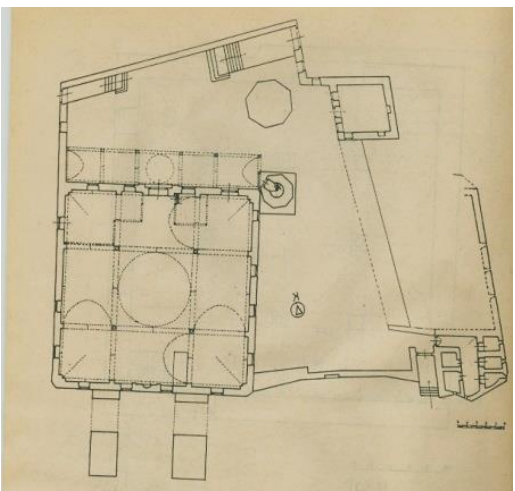

Plan 6. Keban Yusuf Ziya Paşa Külliyesi (F. Şancı'dan) 


\section{EXTENDED ABSTRACT}

Gürün hell under the rule of several states before Turks conquered Anatolia. With the arrival of Turks in Anatolia, the region was under the rule of states and principalities such as the Danishmends, Seljuks, Mamelukes, Dulkadirs and Ottomans. It stayed under Ottoman Rule after 1516 until the time of the republic, and it is now a district under the province of Sivas in Turkey.

The first restoration of Gürün Ulu Camii [the Great Mosque of Gürün] located in the Gürün district of the province of Sivas in Turkey and believed to be built before the third quarter of the 15th century was started in 1850, while this restoration process was completed in 1922. The building, which has reached our time with various changes, reflects the significant characteristics of a period of Turkish art with its remaining plan and ornaments, although it has lost its original form of construction.

The outwardly-splayed windows on the original walls of the building confirm that the building, as described in its epigraph, actually had a vault or wooden ceiling, and the outer part was earth-sheltered.

Gürün Ulu Camii was built on a slightly sloped land, and it was opened to the outside by four windows in the direction of Mecca, two windows and a door in the West and three windows with pointed arches in the East. In addition to these, while two outwardly-splayed windows were included on each of the outer façades, these were not reflected in the inner space. In the northern façade, there is a covered, two-story narthex that was built after the fact. In this façade, the base of the minaret partly exceeds from the main walls of the building. On the minaret base that remained from the first construction process, the minaret with a cylindrical body that was renewed in the restoration process of 1850 rises.

The interior space is entered through the wooden leaf door that shows Baroque characteristics. This area includes a central structure with a dome in the middle carried by four pillars, a barrel vault that supports the dome from four sides and mirror vaults that cover the gaps in the corners.

In the alter with a rounded arch that is found on the wall in the direction of Mecca, its structure was restricted with two grooved columns with two Corinthian caps placed on each base on two sides. The outer columns were ornamented with surrounding ivy. The surfaces of the bases were taken as two panels, and in each panel, one garland hanged on vases was placed. 
There are also some indications that the upper cover of the building in its current state was changed later. The vault covers that are found in the South of the building with higher thicknesses than the narrow ones in the North and the outwardly-splayed windows that are seen from outside on the three façades but not shown from inside suggest significant alterations such as extension of the building towards the north. The outwardly-splayed windows stayed very low. It is understood that the main walls were increased to be able to fit the new cover. The low level of the outwardly-splayed windows indicate that, as stated in the epigraph, the building could originally have a flat roof or vault cover. This is because we have not observed implementation of outwardlysplayed windows in an advanced approach of planning such as a central structure. These windows show that there was a structural alteration in the building, and they must belong to the first construction process, which was before the restoration in 1850 .

Considering the final form of the building, it may be seen that its roots in Turkish architecture may be traced back to pre-Anatolian Turkish architecture. The first known example of the tradition of centrally structured mosques is the Hazara Winter Mosque built by the Karakhanids in the 11th century. The central dome that is found in the building was supported by barrel vault covers from four sides, and domes smaller than the main dome were used in the gaps in the corners. The first building with a central structure schema in Anatolia is the Tokat Garipler Mosque which is dated to the period of Danishmend Gazi (10861104), which included a central dome that was placed onto a load-bearing system consisting of four pillars and columns that were placed between them. This arrangement was achieved by removing the corner domes and the vault covers next to them and surrounding the main dome with cradle vaults.

Although no information could be reached about the first construction of the building, some architectural elements that have remained from the first construction process allow dating. The outwardly-splayed windows that are found on the East, West and South façades of the structure and the prismatic triangle-shape transition elements found on the basis of the minaret indicate the early period. These transition elements in the minaret were also found in the minaret of Darende Ulu Camii (1468-1472) and the Maraş Hatuniye Mosque (1509). As the outwardly-splayed windows found on the façades were not used in an advanced period of Ottoman architecture, it is needed to date this building to a pre-Ottoman period. The transitions in the base of the minaret indicate the periods where the Mamelukes and Dulkadir Principality were dominant on the region. Due to the proximity of Gürün and Darende, this mosque should be contemporaneous with Darende Ulu Camii. Accordingly, we may state that the first construction of the building may be around the third quarter of the 15th century at the latest. 